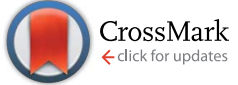

Cite this: RSC Adv., 2016, 6, 11591

Received 6th November 2015 Accepted 5th January 2016

DOI: 10.1039/c5ra23415h

www.rsc.org/advances

\section{Dual functionality of amphiphilic 1-alkyl-3- methylimidazolium hydrogen sulfate ionic liquids: surfactants with catalytic function}

\begin{abstract}
Janusz Nowicki, ${ }^{\text {a }}$ Justyna Łuczak $^{\star b}$ and Dorota Stańczyk ${ }^{a}$
A series of amphiphilic 1-alkyl-3-methylimidazolium hydrogen sulfate ionic liquids were synthesized. Acidic hydrogen sulfate ionic liquids with the alkyl chains $C_{6}-C_{14}$ are characterized by good surface properties. Their surface properties (adsorption and micellization parameters, degree of ionization of micelles, Krafft temperatures and thermodynamic parameters) were determined. Synthesized ionic liquids were applied as a co-catalyst in an oxirane ring opening reaction in epoxidized fatty acid methyl esters (FAME). Their co-catalytic activities were determined and discussed as a function of their structure and surface properties. It was found that the co-catalytic properties, both conversion and selectivity, of alkylimidazolium hydrogen sulfate ionic liquids noticeably depended on the alkyl chain lengths, and in consequence their properties.
\end{abstract}

\section{Introduction}

The term "ionic liquids" (ILs) describes a group of organic salts, characterized by having melting points below $100{ }^{\circ} \mathrm{C}$ and a number of unusual and diverse properties, for example, low vapor pressure, non-flammability, high conductivity, thermal stability, good solvation properties and so on. The extensive interest in the synthesis, physicochemical properties as well as application of ILs is a consequence of their extreme versatility, because their properties can be readily modified by varying the cation and anion species. ${ }^{1}$ Most of the ILs described in the literature are characterized by relatively strong ionic asymmetry, their low melting points, and they exhibit the characteristics of being amphiphilic compounds with specific hydrophilic and lipophilic centers. Intensive studies on the surfactant properties of the ILs have been carried out for many years. These results obtained in particular for imidazolium ILs have been described in many papers and also collected in several reviews. ${ }^{2-16}$ Based on a variety of methods such as surface tension measurements, ${ }^{17}$ conductivity, ${ }^{4}$ calorimetry, ${ }^{18,19}$ spectroscopy ${ }^{20}$ and so on, as well as molecular dynamics, ${ }^{21}$ the relationship between alkyl chain length in the IL cation as well as the anion structure and susceptibility to micellar aggregate formation was proposed. Up to the present time, the surface activity and aggregation behavior of amphiphilic ILs have been used in many synthetic, catalytic and separation applications. For example, Li et al. applied micellar solutions of polymeric ILs in the preparation of gold

"Institute of Heavy Organic Synthesis, Blachownia, Energetyków 9, 47-225 Kędzierzyn-Koźle, Poland. E-mail: nowicki.j@icso.com.pl

${ }^{b}$ Gdanisk University of Technology, Faculty of Chemistry, Department of Chemical Technology, G. Narutowicza 11/12, 80-233 Gdańsk, Poland nanoparticles with a controlled size because of the combination of the unique chemical and physical properties of ILs and the micellar template. ${ }^{22}$ Dodecyltrimethylammonium bromide micelles can act as a size- and structure-directing template as well acting as a stabilizing agent for the formation of iron oxyhydride $(\alpha-\mathrm{FeOOH})$ nanoparticles. ${ }^{23}$ The surface active properties of ILs were used for the modification of the zeolite surface to enhance the adsorptive removal of anionic contaminants such as chromate from water. ${ }^{24}$ Pino $e t$ al. proposed the application of the 1-hexadecyl-3-methylimidazolium bromide micellar solution for the extraction of the polycyclic aromatic hydrocarbons from sediments. ${ }^{25}$ It was revealed that ILs cannot be considered as only common cationic surfactants. The structure of the cation is far more complex than that of conventional quaternary ammonium salts that are the most popular cationic surfactants. In the molecule of imidazolium ILs, with a partially delocalized positive charge constituting the nucleus, it is possible to define a number of interactions (van der Waals, $\pi-\pi$ interactions, hydrogen bonding) that have a significant impact on their surface properties, formation of micelles, and, consequently, on the processes utilizing them.

Furthermore, many chemical reactions, involving ILs, are carried out in biphasic systems assisted by an amphiphilic catalyst. ${ }^{23,24}$ For this type of process, the progress of reaction is determined by diffusion taking place between the two immiscible phases. In reactions which proceed with the use of the catalysts, besides isolation and purification of the product, an important element is to develop a method for catalyst separation from the post-synthesis mixture. However, most of these methods do not often work well when ILs are used as catalysts because of poor solubility in the catalytic phase, particularly when it is water. However, solubilizing the properties of ionic 


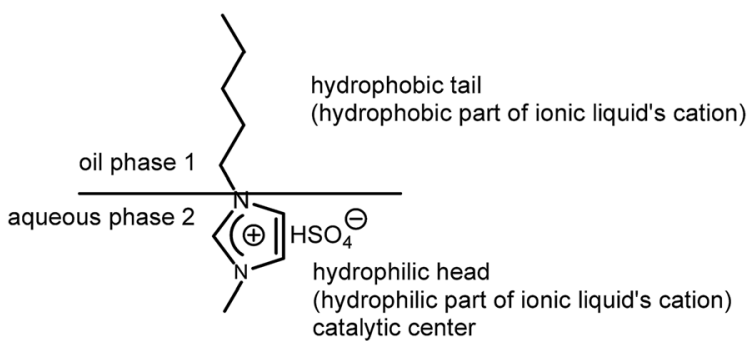

Scheme 1 Amphiphilic IL - surfactant with catalytic function.

liquids in combination with their surface properties can be a very promising alternative for the classical two-phase catalysis, as it is similar to common phase transfer catalysis. ${ }^{26-31}$ One of the features that distinguishes ILs from most common solvents is their dual functionality in various aspects. The dual functionality of ILs in the "classic" form, where the IL plays both the role of solvent and the catalyst, has been well described in the literature. ${ }^{32-37}$ An interesting example of the dual functionality of ILs was reported by Alizadeh. ${ }^{38}$ In the condensation of aromatic carbonyl compounds with nitroalkanes, 2-hydroxyethylammonium formate IL was used. It emerged that the ammonium proton participated in the protonation of the aldehyde group in the first step of the synthesis.

In the studies reported in this paper, the aim was to investigate the dual functionality of the acidic ILs by means of both of catalytic and amphiphilic properties. For the first time, the synthesis and use of the amphiphilic Brønsted acidic ILs as effective co-catalysts in a biphase catalytic process of nucleophilic addition of water to an oxirane ring are reported. This reaction proceeds according to an $\mathrm{S}_{\mathrm{N}} 1$ mechanism and requires acidic catalysts. In this study, 1-alkyl-3-methylimidazolium hydrogen sulfate ILs are used because their surface properties, will strongly affect the development of the interfacial surfaces. However, the Brønsted acidic catalytic center will catalyze the process more efficiently (Scheme 1). In this respect, the surface properties of the ILs were correlated with their catalytic activity in the reaction of epoxydized methyl oleate with water as the nucleophile. Addition of water to the oxirane ring in epoxidized fatty acid derivatives turns it to the corresponding glycols, which are valuable oleochemical by-products. Finally, based on the experimental studies, the role of the IL structure as well as its catalytic activity in the biphasic reaction was proposed.

\section{Materials and methods}

\subsection{Materials}

1-Bromohexane (99\%), 1-bromooctane (99\%), 1-bromodecane (99\%), 1-bromododecane (99\%) and 1-bromotetradecane were purchased from Tokyo Chemical Industry (TCI). 1-Methylimidazole was obtained from Merck Millipore (Poland). Potassium bisulfate Puriss $\left(\mathrm{KHSO}_{4}, 99 \%\right)$ was obtained from SigmaAldrich (Poland). Octyltrimethylammonium chloride (OTMAC; 99\%) was obtained from Sigma-Aldrich. Ethanol Puriss and diethyl ether Puriss were obtained from POCH (Poland). All the chemicals were used without drying or any further purification.
Epoxidized methyl oleate was synthesized according to a procedure described in the literature with the use of distilled methyl oleate (minimum $92 \mathrm{wt} \%, \mathrm{GC}$ ), $30 \mathrm{wt} \%$ of aqueous solution of hydrogen peroxide and formic acid as an active oxygen source. ${ }^{39}$

\subsection{Ionic liquid preparation}

All the ILs used in this study were synthesized according to wellknown procedures described in literature. ${ }^{40}$ Thus, a mixture of 1-bromoalkane $(0.2 \mathrm{~mol})$ and 1-methylimidazole $(0.2 \mathrm{~mol})$ were placed in a $100 \mathrm{~mL}$ glass reactor. The mixture was then stirred under a $\mathrm{N}_{2}$ (nitrogen atmosphere) for $18 \mathrm{~h}$ at $90{ }^{\circ} \mathrm{C}$. The oily crude product was washed several times with diethyl ether to remove unreacted reagents. The residual volatile solvent was evaporated under vacuum (1-2 mbar, $2 \mathrm{~h}$ ) to give corresponding imidazolium bromides as light yellow, viscous oils $\left(\mathrm{C}_{6}-\mathrm{C}_{10}\right)$ or a white solid $\left(\mathrm{C}_{12}-\mathrm{C}_{14}\right)$. The obtained imidazolium bromides were then dissolved in $200 \mathrm{~mL}$ of isopropyl alcohol. An appropriate amount of $\mathrm{KHSO}_{4}(20 \%$ molar excess $)$ was added to the solution and stirred at room temperature for $18 \mathrm{~h}$. A white precipitate of potassium bromide was filtered off and the clear filtrate was evaporated under vacuum to give hydrogen sulfate ILs as yellowish oils $\left(\mathrm{C}_{6}-\mathrm{C}_{10}\right)$ or hygroscopic solids $\left(\mathrm{C}_{12}, \mathrm{C}_{14}\right)$.

\subsection{Analytical methods}

The composition of the post-synthesis mixtures were determined using gas chromatography (GC) with mass spectrometric (MS) detection. Analyses were performed on a HP chromatograph model 7890A (Agilent) equipped with a mass selective detector type $7000 \mathrm{GC} / \mathrm{MS}$ Triple Quad MS detector. For analysis an HP-5ms column (length $=30 \mathrm{~m}$, diameter $=0.25 \mathrm{~mm}$, working temperature of $70-280{ }^{\circ} \mathrm{C}$, detector temperature of $300{ }^{\circ} \mathrm{C}$, helium as carrier gas) was used. Analytical data were obtained using MassHunter software (Agilent).

The epoxide numbers of both the raw materials and the products were determined using Fourier-transform infrared spectroscopy (FTIR). For the determination of epoxide number, bands 916 and $835 \mathrm{~cm}^{-1}$ were assigned to the epoxy ring stretching region. FTIR analyses were performed on a Thermo Scientific FTIR Nicolet 6700 spectrophotometer. The reflection technique with horizontal attenuated total reflectance using Smart ARK (Thermo Scientific), with zinc selenide crystals, the number of reflections was 7 , and the sample penetration depth by the IR beam was $1.11 \mathrm{~m}$. The hydroxyl numbers were determined according to DIN 53240.

Surface tension $(\sigma)$ of the IL solutions were measured at $25 \pm$ $0.1{ }^{\circ} \mathrm{C}$ using a video-based optical contact angle meter (OCA 15, DataPhysics), together with the supportive software, SCA22 (pendant drop method), and a resolution of $\pm 0.01 \mathrm{mN} \mathrm{m}^{-1}$. The temperature of the samples were controlled using a thermostatic water bath (AD07R-20, PolyScience). The error calculation was performed using the DataPhysics software.

The critical micelle concentration (CMC) values of the IL solutions were also confirmed by the results of conductivity $(\kappa)$ and isothermal titration calorimetry (ITC) methods. The conductivity measurements were performed at $25 \pm 0.1{ }^{\circ} \mathrm{C}$ using a conductivity meter equipped with an autotitrator (CLS/M/07/ 
06, Cerko Lab System, Poland) and a microconductivity electrode (EPST-2ZA, Eurosensor, Poland). A thermostatic water bath (PolyScience 9106, Cole-Palmer, USA) was used to maintain a stable temperature during the measurements. The degree of ionization of the micelles $(\beta)$ was calculated from the ratio of the $\mathrm{d} \kappa / \mathrm{d} c$ slopes of the two linear fragments of the conductivity curves. $^{\mathbf{4 1 , 4 2}}$ The conductivity method was also applied for the Krafft temperature $\left(K_{\mathrm{T}}\right)$ determination. For this purpose the aqueous solutions of ILs at concentrations ten times their CMC were placed in a refrigerator at a temperature of $253 \mathrm{~K}$ for at least $24 \mathrm{~h}$ to ensure complete precipitation of the salts in the form of hydrated crystals. The temperature $(T)$ of the sample was then raised gradually using a thermostat bath and the conductivity of the sample was measured under stirring until a steady value was reached. ${ }^{43}$ The measurements were carried out until the turbid solution became transparent. The Krafft temperature was taken as a discontinuity in the conductivity versus temperature curve. This temperature is analogous to the point of complete clarification of the solution judged visually.

The ITC experiments were performed with a Nano-Isothermal Titration Calorimeter III [Calorimetry Sciences Corporation (CSC), USA]. The IL solutions with concentrations of about ten times higher than the expected CMC values were used to observe the demicellization process. The titration experiment consisted of 48 injections of $5.15 \mu \mathrm{L}$ aliquots of the IL into the sample cell loaded with $958 \mu \mathrm{L}$ of water after a stable base line was achieved. The enthalpograms were created using Titration BindWorks software provided by CSC. Using the enthalpograms, the enthalpy of demicellization $\left(\Delta H_{\mathrm{dm}}\right)$ and CMC were determined. ${ }^{\mathbf{1 8 , 4 3}}$ The surface excess concentration, $\Gamma_{\max }$, and the minimum area per surfactant molecule, $A_{\min }$, at the air/solvent interface were calculated using surface tension measurement values by means of eqn (1) and (2):

$$
\begin{gathered}
\Gamma_{\max }=-\frac{1}{R T}\left[\frac{\mathrm{d} \gamma}{\mathrm{d} \ln c}\right]_{T, p} \\
A_{\min }=\frac{10^{16}}{N_{\mathrm{A}} \Gamma_{\max }}
\end{gathered}
$$

where $R$ is the gas constant, $T$ is the absolute temperature, $N_{\mathrm{A}}$ is Avogadro's number, $\gamma$ is the surface tension, and $c$ is the concentration of the surfactant in the solution. Surface pressure at the CMC, $\Pi_{\mathrm{CMC}}$, was obtained using eqn (3):

$$
\Pi_{\mathrm{CMC}}=\gamma_{\mathrm{o}}-\gamma_{\mathrm{CMC}}
$$

The Gibbs free energy of micelle formation, $\Delta G_{\mathrm{m}}$, of a nonionic surfactant is related to the CMC by the following formula:

$$
\Delta G_{\mathrm{m}}=R T \ln x_{\mathrm{m}}
$$

where $x_{\mathrm{m}}$ is the CMC expressed in mole fraction units. The standard entropy, $\Delta S_{\mathrm{m}}$, of the micellization was calculated from eqn (5):

$$
\Delta S_{\mathrm{m}}=\frac{\left(\Delta H_{\mathrm{m}}-\Delta G_{\mathrm{m}}\right)}{T}
$$

where $T$ is the temperature.

\subsection{Nucleophilic addition of water to the epoxidized methyl oleate}

The reactions were carried out in a $100 \mathrm{~mL}$ laboratory glass reactor equipped with a mechanical stirrer and a water jacket connected with thermostat. Epoxidized methyl oleate $(50 \mathrm{~g})$, an aqueous solution of sulfuric acid $\left(\mathrm{H}_{2} \mathrm{SO}_{4} ; 63 \mathrm{~mL}\right)$ and additional co-catalyst were placed in the reactor, heated to the desired temperature (thermostat) and stirred at $500 \mathrm{rpm}$ for $7 \mathrm{~h}$. After 1, 3 and $5 \mathrm{~h}$ of reaction time, samples were taken and analyzed. After completion of the reaction, the organic phase was washed until a neutral pH was reached and the sample was dried. An analogous procedure was applied in relation to the analytical samples.

\section{Results and discussion}

\subsection{Surface properties of alkylmethylimidazolium hydrogen sulfate ILs}

The solubility of ionic amphiphilic compounds in aqueous solutions is highly temperature-dependent. The characteristic feature is the $K_{\mathrm{T}}$, which is the minimum temperature at which the solubility of the salt monomer becomes high enough to start forming micellar aggregates, thus corresponding to the onset of the surface activity of the compound. First of all, the temperature range at which micellization of the ILs may occur was investigated. The selected relationship of the conductivity measurements of the 1-tetradecyl-3-methylimidazolium hydrogen sulfate $\left(\left[\mathrm{C}_{14} \mathrm{mim}\right] \mathrm{HSO}_{4}\right)$ solution versus temperature (in the range of $0-20^{\circ} \mathrm{C}$ ) used to determine the $K_{\mathrm{T}}$ is presented in Fig. 1.

Below the $K_{\mathrm{T}}$, the surfactant is in the solid crystalline hydrated state, therefore the conductivity of the sample gradually increases with temperature because of the progressive increase of its solubility in water. At the $K_{\mathrm{T}}$, a dramatic rise in the conductivity was observed reflecting an equilibrium among the ordered, solvated solid phase, dispersed monomers, and micellar aggregates. The lower slope in the conductivity profile after the Krafft point is related to the limited mobility of the formed micelles as compared to the free ions. The $K_{\mathrm{T}}$ is strongly dependent on the surfactant structure, that is, the

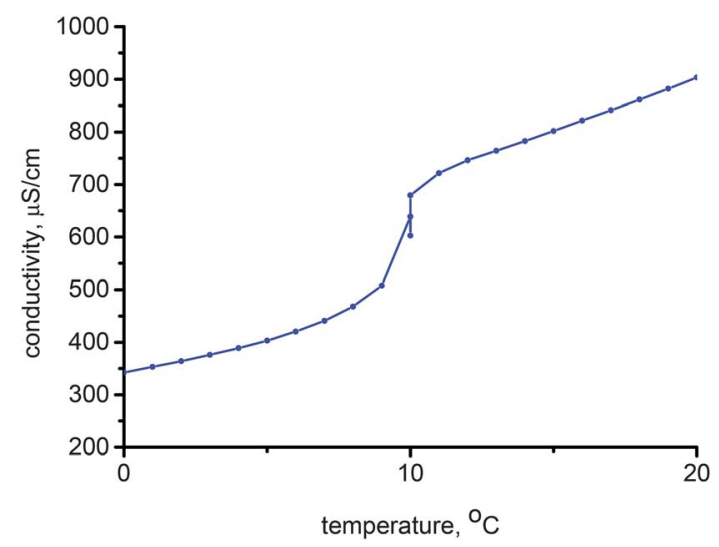

Fig. 1 Krafft temperature $\left(K_{T}\right)$ determination for 1-tetradecyl-3methylimidazolium hydrogen sulfate. 
alkyl chain length, the type of polar head, the nature of the counter-ion as well as possible interactions (particularly hydrogen bonding). The results obtained for ILs presented in this study confirmed chain length dependency. Aqueous solutions of the ILs with an alkyl chain length below or equal to 12 carbon atoms did not indicate a clear $K_{\mathrm{T}}$ above $0{ }^{\circ} \mathrm{C}$. Therefore, the $K_{\mathrm{T}}$ either falls to below $0{ }^{\circ} \mathrm{C}$ or does not exist in these conditions because the solubility curve does not intersect the Krafft boundary, but rather the ice boundary. ${ }^{43,44}$ Only $\left[\mathrm{C}_{14} \mathrm{mim}\right] \mathrm{HSO}_{4}$ IL have a clearly detectable $K_{\mathrm{T}}$ at $10{ }^{\circ} \mathrm{C}$. The $K_{\mathrm{T}}$ determined for the $\mathrm{C}_{14}$ compound was higher than those which were characteristic for tetradecyltrimethylammonium chloride $\left(<0 \quad{ }^{\circ} \mathrm{C}\right)$ and bromide $\left(\sim 0{ }^{\circ} \mathrm{C}\right)$, as well as 1-tetradecyl-3methylimidazolium chloride $\left(<0{ }^{\circ} \mathrm{C}\right)$ indicating the lower hydrophilicity of the hydrogen sulfate ILs. Nevertheless, these results are favorable from a practical point of view because of the wide range of use.

3.1.1 Effect of hydrocarbon chain length and the type of counterion. In order to investigate the surface properties of 1alkyl-3-methylimidazolum hydrogen sulfate ILs the surface tension and conductivity methods were used. The surface tension measurements versus concentration of various ILs are shown in Fig. 2, whereas selected conductivity results are presented in Fig. 3. As a result of their amphiphilic structure and positive charge on the nitrogen atom, all the ILs used in this study have the ability to adsorb at the air/water interface, and to reduce surface tension of the aqueous solutions eventually forming micellar aggregates. It is well known that the hydrocarbon chain length, as well as the counterion type are the most important factors determining the interface behavior and surface activity of the amphiphilic compounds. Therefore, behavior that was typical for quaternary ammonium compounds was observed, that is, the longer the chain length in the cation, the lower the concentration at which surface tension lowering begins. Micelles are not surface active agglomerates of amphiphilic compounds, therefore the surface tension of the dispersion after passing the CMC is almost constant (the plateau region in the surface tension isotherms). Furthermore, micellar aggregates have a lower mobility in comparison with monomers in solution, therefore the lower slope after the discontinuity was observed in the conductivity curve. The adsorption and micellization parameters, which characterize the behavior of the ILs in the aqueous systems, are shown in Table 1.

A decrease of the CMC from near $600 \mathrm{mM}$ to about $2 \mathrm{mM}$ was observed with increase of the number of the carbons atoms in the alkyl chain of the imidazolium cation from 6 to 16. This confirms that elongation of the hydrocarbon chain facilitates micelle formation because of increased energetically unfavorable contact of the chains with water, stronger hydrophobic interactions between the alkyl chains and the more delocalized charge reducing the electrostatic repulsion. An analogous decrease in the CMC values was also observed for ILs with different anions, for example, $\left[\mathrm{C}_{n} \mathrm{mim}\right] \mathrm{Cl},{ }^{\mathbf{1 7}, 43}$ $\left[\mathrm{C}_{n} \mathrm{mim}\right] \mathrm{Br}^{16,47}$ and $\left[\mathrm{C}_{n} \mathrm{mim}\right] \mathrm{BF}_{4} \cdot{ }^{48}$ Comparing the CMC values of the ILs with different anions the following order was deduced $\left[\mathrm{C}_{n} \mathrm{mim}\right] \mathrm{BF}_{4}<\left[\mathrm{C}_{n} \mathrm{mim}\right] \mathrm{HSO}_{4} \approx\left[\mathrm{C}_{n} \mathrm{mim}\right] \mathrm{Br}<\left[\mathrm{C}_{n} \mathrm{mim}\right]$

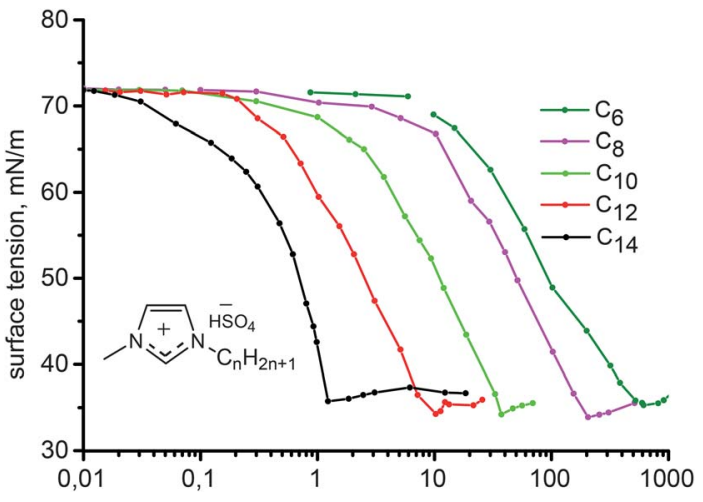

Fig. 2 Surface tension data vs. aqueous solutions concentration of 1alkyl-3-methylimidazolium hydrogen sulfate ILs isotherm $\left(25^{\circ} \mathrm{C}\right)$.

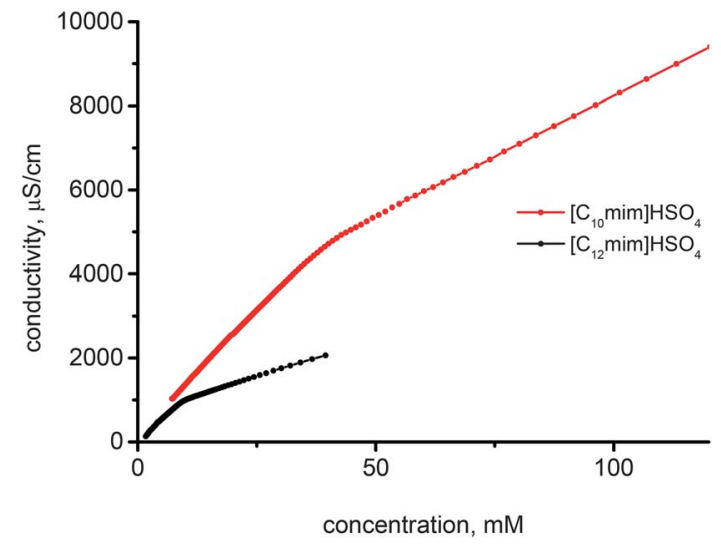

Fig. 3 Exemplary results of specific conductivity variation vs. concentration of $\left[\mathrm{C}_{10} \mathrm{mim}\right] \mathrm{HSO}_{4}$, and $\left[\mathrm{C}_{12} \mathrm{mim}\right] \mathrm{HSO}_{4} \mathrm{ILs}$ in aqueous solutions at $25^{\circ} \mathrm{C}$.

Cl. This sequence reflects hydration, polarizability and size of the anions, thus, larger, less hydrated (more hydrophobic) anions easier interact with the micelle surface, thereby decreasing electrostatic repulsion and facilitating micelle formation. This can be confirmed by the values of the degree of micelle ionization $(\beta)$ which is estimated on the basis of the conductivity measurements that are lower than that for imidazolium ILs with the $\mathrm{BF}_{4}$ anion (presented as degree of counterion association to the aggregates $)^{48}$ and higher than that determined for salts containing the $\mathrm{Cl}$ anion. ${ }^{43}$ In addition, ionization of the micelles increases with elongation of the alkyl chain length because of the larger size of micelles formed by the more highly ordered and compact micellar structures of the higher homologues.

The relationship between CMC and the number of carbon atoms in the alkyl chain $(x)$ for a homologous series of linear single-chain amphiphiles can be described by the logarithmic rule:

$$
\log \mathrm{CMC}=A-B x
$$


Table 1 The adsorption and micellization parameters determined for 1-alkyl-3-methylimidazolum hydrogen sulfates

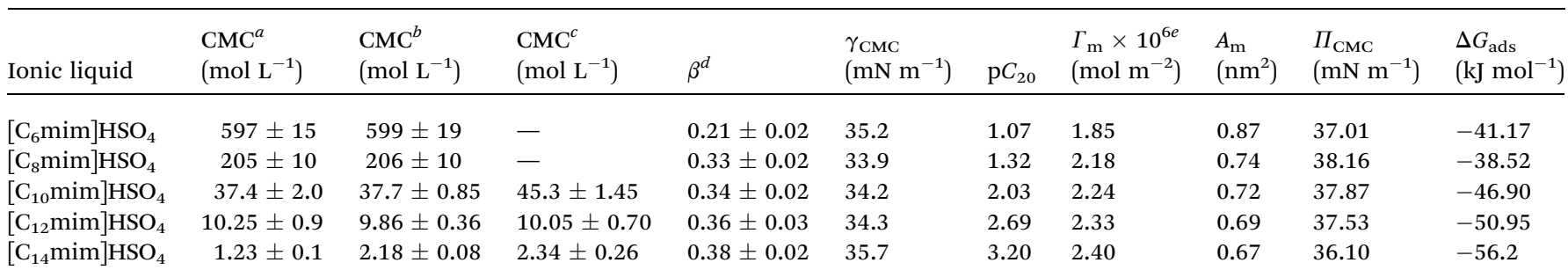

${ }^{a}$ Surface tension. ${ }^{b}$ Conductivity. ${ }^{c}$ Calorimetry. ${ }^{d} \beta$ - the degree of ionization, $\gamma_{\mathrm{CMC}}-$ the surface tension at the $\mathrm{CMC}$; p $C_{20}-$ the surfactant concentration required to reduce the surface tension of the solvent by $20 \mathrm{mN} \mathrm{m}^{-1} .{ }^{e} \Gamma_{\max }$ - the maximum surface excess concentration; $A_{\mathrm{m}}-$ the minimum area per molecule at the interface; $\Delta G_{\text {ads }}$ - free energy of adsorption.

where $A$ and $B$ are empirical constants. The $A$ value depends on the type and number of the polar head groups in the amphiphile, whereas the value of $B$ indicates the contribution of the methylene group in the hydrophobic chain to the micelle formation (Fig. 5). Micellization is favored by smaller values of $A$ or larger values of $B{ }^{49}$ The values of $A$ and $B$ calculated using eqn (6) for [ $\left.\mathrm{C}_{n} \mathrm{mim}\right] \mathrm{HSO}_{4}$ are 4.92 and 0.34 , respectively, and are similar to proper $A, B$ constants describing the homologues series of the 1-alkyl-3-methyimidazolium salts with $\mathrm{Cl}$ and $\mathrm{Br}$ anions. ${ }^{10}$
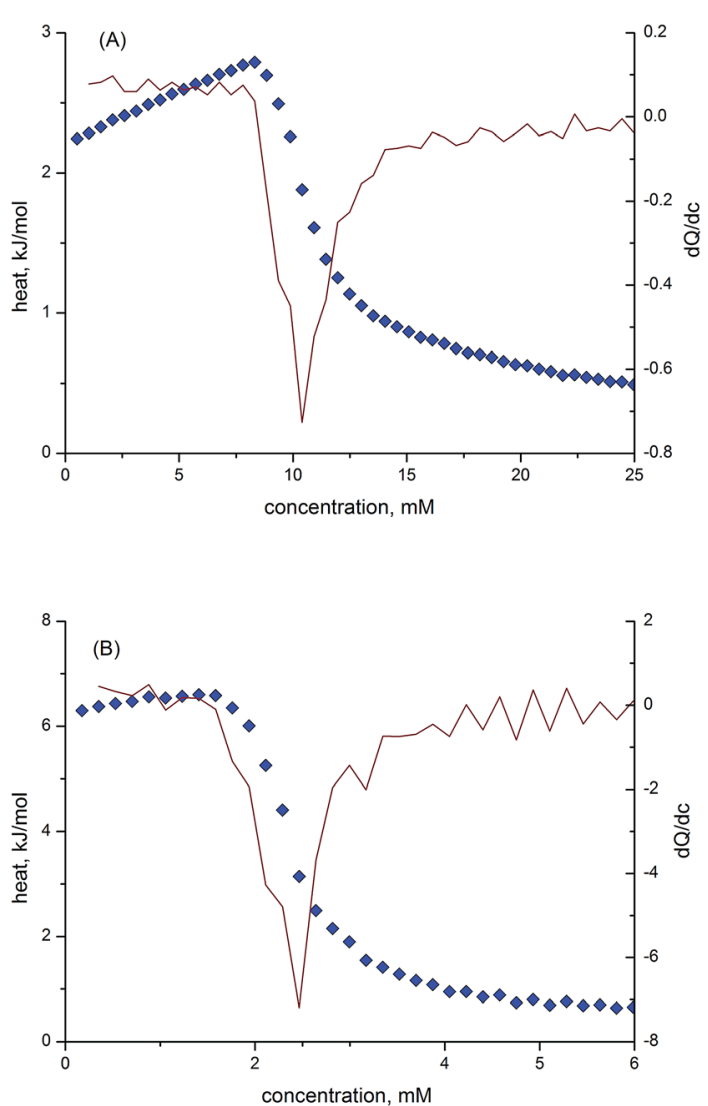

Fig. 4 Enthalpograms of ITC titration determined for $\left[\mathrm{C}_{12} \mathrm{mim}\right] \mathrm{HSO}_{4}$ aqueous solution at a concentration of $102.5 \mathrm{mM}$ into water (A), $\left[\mathrm{C}_{14} \mathrm{mim}\right] \mathrm{HSO}_{4}$ aqueous solution at a concentration of $34.7 \mathrm{mM}$ into water (B). The first derivative $(\mathrm{d} Q / \mathrm{dc})$ indicates the $\mathrm{CMC}$ of the solution.

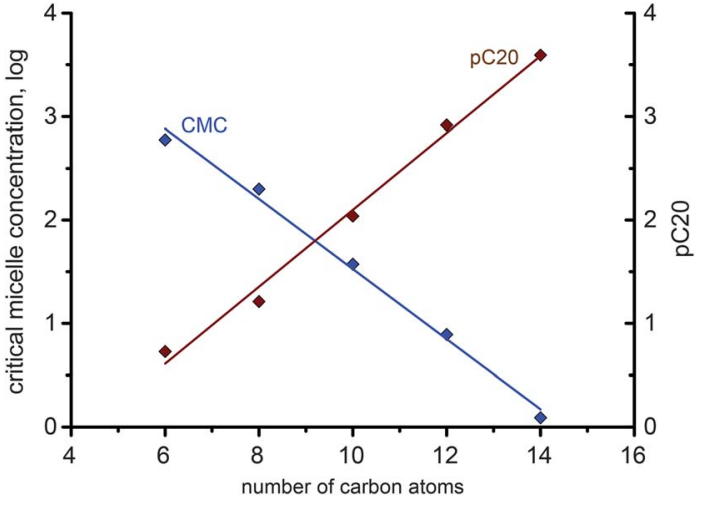

Fig. 5 Logarithmic dependence of $C M C$ and $p C_{20}$ on the alkyl chain length of 1-alkyl-3-methylimidazolium hydrogen sulfate ILs.

The IL adsorption efficiency, the concentration at which the surfactant provides a surface tension reduction of $20 \mathrm{mN} \mathrm{m}^{-1}$ $\left(\mathrm{p} C_{20}\right)$, was observed to increase from 1.07 for $\left[\mathrm{C}_{6} \mathrm{mim}\right] \mathrm{HSO}_{4}$ to 3.2 for the IL with the longest chain length in the imidazolium cation $\left(e . g\right.$., $\left.\mathrm{C}_{14}\right)$. The higher $\mathrm{p} C_{20}$, the more efficiently the IL adsorbs at the interface and reduces surface tension. The values of surface tension at CMC, $\gamma_{\mathrm{CMC}}$, were found to be close to 34-35 $\mathrm{mN} \mathrm{m}^{-1}$ for all of the ILs, whereas the surface pressure values, $\Pi_{\mathrm{CMC}}$, were calculated to be in the range of $36-38 \mathrm{mN} \mathrm{m}^{-1}$. Both of these parameters describe the effectiveness of the surfactant to adsorb at the interface and reduce surface tension, and for ionic compounds (such as ILs) are controlled by CMC, solubility or $K_{\mathrm{T}}{ }^{44,50}$ The efficiency and effectiveness of the 1-alkyl-3methylimidazolium hydrogen sulfates were found to be consistent, in other words, the more efficient ILs, the more effective they are. When comparing these parameters with ILs possessing different anions, it can be observed that hydrogen sulfate derivatives are more surface active compounds than halogen-based salts. ${ }^{48}$

The estimated area per IL ion pair at the air/water interface, $A_{\text {min }}$, obtained from the Gibbs adsorption isotherm (eqn (1) and (2)), appeared to decrease from 0.87 to $0.67 \mathrm{~nm}^{2}$ with increasing alkyl chain length in the imidazolium cation. The area occupied by the amphiphilic compound, reflecting the surface arrangement of surfactants at the air/liquid interface, was determined by the hydrophobic chain cross-sectional area, and the area 
required for closest packing of the head group. Therefore, this provides information on the degree of packing and the orientation of the adsorbed surfactant molecules. The maximum surface excess concentration at the air/water interface, $\Gamma_{\max }$, was observed to increase from $1.85 \times 10^{-6} \mathrm{~mol} \mathrm{~m}^{-2}$ as determined for $\left[\mathrm{C}_{6} \mathrm{mim} \mathrm{HSO}_{4}\right.$ to $2.40 \times 10^{-6} \mathrm{~mol} \mathrm{~m}{ }^{-2}$ for $\left[\mathrm{C}_{14} \mathrm{mim}\right]$ $\mathrm{HSO}_{4}$. The behavior of the $\left[\mathrm{C}_{n} \mathrm{mim}\right] \mathrm{HSO}_{4}$ ILs is characterized by a larger $\Gamma_{\max }$ and correspondingly lower $A_{\min }$ values than $\left[\mathrm{C}_{n} \mathrm{mim}\right] \mathrm{Br}$, indicating a denser arrangement of hydrogen sulfate-based compounds at the air-water interface compared to that of $\left[\mathrm{C}_{n} \mathrm{mim}\right] \mathrm{Br}^{49}$

3.1.2 Thermodynamics of micellization. The thermodynamic parameters of the micellization process provide valuable information about the driving force of the self-assembly of ILs. By using the ITC technique, a direct result of the CMC values as well as enthalpy of demicellization $\left(\Delta H_{\mathrm{dm}}\right)$, and thereby the enthalpy of micellization $\left(\Delta H_{\mathrm{m}}\right),{ }^{45,46}$ can be determined. The ITC titration peaks obtained by addition of concentrated IL solution towards water were integrated and normalized taking into account the number of moles of the solute. The selected enthalpograms obtained for ILs with the $\mathrm{C}_{12}$ and $\mathrm{C}_{14}$ alkyl chain of the imidazolium cation are as shown in Fig. 4. At a concentration below the CMC (titration of water with concentrated IL solution; first part of the enthalpogram), an enthalpic effect is a consequence of the transition: micelles $\rightarrow$ monomers (heat of micelle dilution, demicellization and dilution of monomers in the solvent). Micellar aggregate formation is visible as a sharp increase of the heat effect (the second region in the enthalpogram). At concentrations above the CMC, the third part of the enthalpogram, the heat effect arises from the dilution of the concentrated micelles into the micellar solution. Demicellization enthalpy was calculated from a difference between the enthalpy values of the terminal and initial regions of the enthalpogram $\left(\Delta H_{\mathrm{dm}}\right)$, as was previously shown in research by Łuczak et al. and Jiang et al. ${ }^{\mathbf{1 8 4} 3}$ The CMC was taken as the surfactant concentration at the midpoint of the titration curve inflection (the first derivative of the line from where the integrated peaks reach maximum).

The enthalpy of micellization determined by the ITC method as well as the thermodynamic parameters, $\Delta G_{\mathrm{m}}$, and $\Delta S_{\mathrm{m}}$, calculated using eqn (4) and (5) are shown in Table 2. The values of free energy of micellization are negative, indicating a spontaneous micellization process. As was expected, elongation of the hydrocarbon chain length facilitates micelle formation. The experiments revealed that the micellization of the ILs with $\mathrm{C}_{10^{-}}$ $\mathrm{C}_{14}$ alkyl chains at $25{ }^{\circ} \mathrm{C}$ is exothermic, whereas for $\mathrm{C}_{8}$ chains, the reaction is endothermic and $\Delta H_{\mathrm{m}}$ decreases with increasing chain length. Based on the observed trend, it can be assumed that micellization of the ILs with an alkyl chain shorter than $\mathrm{C}_{8}$ is endothermic. The higher $\Delta H_{\mathrm{m}}$ values are because of the higher energy required to release the solvent molecules from the hydration layer and the water cage surrounding the hydrophilic and hydrophobic domains of the amphiphilic compound. The contribution to the overall $\Delta H_{\mathrm{m}}$ value also have energy that is released when the hydrocarbons are transferred to the micelle and the hydrogen bonding structure of the water around the micelle is recreated. ${ }^{43,51}$ Higher energy demands
Table 2 Thermodynamic parameters of selected $\left[\mathrm{C}_{n}\right.$ mim $] \mathrm{HSO}_{4}$ micellization in aqueous solution determined by calorimetry

\begin{tabular}{lcll}
\hline Ionic liquid & $\Delta H_{\mathrm{m}}\left[\mathrm{kJ} \mathrm{mol}^{-1}\right]$ & $\Delta G_{\mathrm{m}}\left[\mathrm{kJ} \mathrm{mol}^{-1}\right]$ & $T \Delta S_{\mathrm{m}}\left[\mathrm{kJ} \mathrm{mol}^{-1}\right]$ \\
\hline$\left[\mathrm{C}_{8} \mathrm{mim}\right] \mathrm{HSO}_{4}$ & $0.84 \pm 0.6$ & -21.23 & 22.1 \\
{$\left[\mathrm{C}_{10} \mathrm{mim}\right] \mathrm{HSO}_{4}$} & $-0.49 \pm 0.8$ & -29.25 & 26.3 \\
{$\left[\mathrm{C}_{12} \mathrm{mim}_{\mathrm{HSO}}\right.$} & $-1.4 \pm 0.2$ & -34.93 & 33.6 \\
{$\left[\mathrm{C}_{14} \mathrm{mim}_{4}\right] \mathrm{HSO}_{4}$} & $-5.1 \pm 0.14$ & -40.34 & 36.0
\end{tabular}

appear because of the shorter chain length in the cation, and as a consequence the higher affinity of the short-chained compounds to water.

An increase of the entropy change is a driving force of the micellization process, being initiated by a highly ordered structure of the solvents, mainly around the hydrophilic part of the surfactant. During micellization, water molecules become reduced in the hydration network providing an increase in $\Delta S_{\mathrm{m}}$ and a decrease in $\Delta G_{\mathrm{m}}$. According to the Gibbs-Helmholz equation, $\Delta H_{\mathrm{m}}$ and $\Delta S_{\mathrm{m}}$ have an opposite effect on the free energy of the micelles' formation. For all of the IL systems, $\Delta H_{\mathrm{m}}$ is lower than $T \Delta S_{\mathrm{m}}$ indicating that they are entropy driven processes.

\subsection{Reaction of epoxydized methyl oleate with water}

Oxirane ring opening by various nucleophiles occurs by one of two different mechanisms, the choice of which depends on the character of the nucleophile. Strong nucleophiles such as Grignard reagents, alkali hydroxides or alkali alcoxides react with the oxirane ring using an $\mathrm{S}_{\mathrm{N}} 2$ substitution mechanism. The key step of this mechanism is the nucleophile attack to the more substituted $\mathrm{C}$ atom of the oxirane ring. Weaker nucleophiles, such as water or alcohols, react with the oxirane ring using an $\mathrm{S}_{\mathrm{N}} 1$ substitution mechanism. The key step of this mechanism is protonation of the $\mathrm{O}$ atom in the oxirane ring. This makes the acid catalysts have a strong positive impact on this reaction. Thus, the reaction of epoxidized methyl oleate with nucleophiles such as water occurs using an $\mathrm{S}_{\mathrm{N}} 1$ substitution mechanism and is catalyzed by various acidic catalysts. For a preliminary assessment of this reaction in conventional reaction conditions and for comparison purposes, a series of experiments with various concentrations of an aqueous solution of $\mathrm{H}_{2} \mathrm{SO}_{4}$ as catalyst were conducted. The results are presented graphically in Fig. 6. As can be seen, the concentration of $\mathrm{H}_{2} \mathrm{SO}_{4}$ has a strong impact on the reaction efficiency. Changes of the epoxide number for a concentration of $1 \mathrm{wt} \%$ were observed to be negligible, however, for a concentration of $5 \mathrm{wt} \%$ after a reaction time of $7 \mathrm{~h}$, the epoxide number decreased to $0 \mathrm{mg}$ potassium hydroxide $(\mathrm{KOH}) / \mathrm{g}$, which corresponds to a conversion of epoxide of $100 \%$.

In the next step, to $1 \mathrm{wt} \%$ of an aqueous solution of $\mathrm{H}_{2} \mathrm{SO}_{4}$, a Brønsted acidic IL, $2 \mathrm{wt} \%$ (based on epoxidized methyl oleate) of $\left[\mathrm{C}_{8} \mathrm{mim}\right] \mathrm{HSO}_{4}$ (chosen as a model IL) was added. The effect of the $\mathrm{IL}$ addition to the reaction system is presented in Fig. 6. Fig. 6 clearly shows, that addition of an acidic IL to a $1 \mathrm{wt} \%$ aqueous solution of $\mathrm{H}_{2} \mathrm{SO}_{4}$ results in a strong increase of the reaction rate, which can be explained by the synergistic effect of 


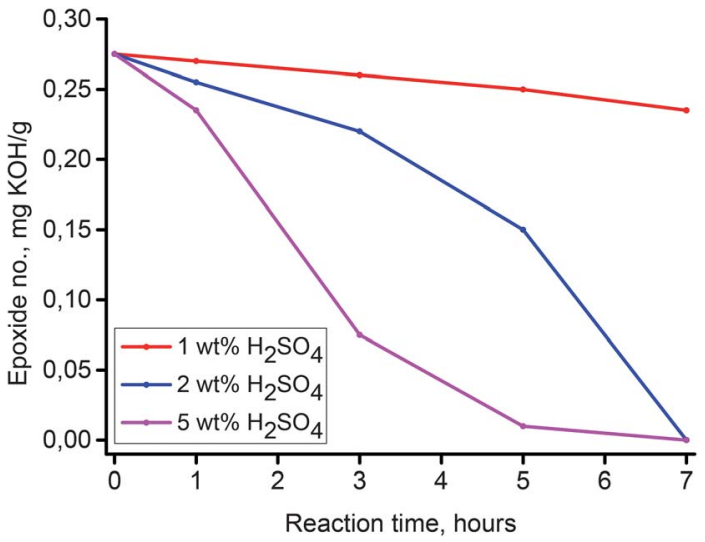

Fig. 6 Effect of concentration of $\mathrm{H}_{2} \mathrm{SO}_{4}$ on epoxide number changes (reaction condition: $T=80^{\circ} \mathrm{C}$ ).

the surface active IL on the catalysis of nucleophilic addition of water to the oxirane ring in the epoxidized methyl oleate. As was stated previously, the surface properties of homologous amphiphilic ILs, are highly dependent on the length of the hydrophobic alkyl chain. In this respect, the analogous reactions of water addition to the oxirane ring using a series of amphiphilic ILs $\left[\mathrm{C}_{n} \mathrm{mim}\right] \mathrm{HSO}_{4},(n=6-14)$ was carried out. The results are depicted in Fig. 7. As is demonstrated by the results shown in Fig. 8, all the ILs used as co-catalysts that were tested are characterized by a strong synergistic effect. After a reaction time of 7 $\mathrm{h}$ the epoxide number $\left(L_{\mathrm{ep}}\right)$ in each of the samples were close to $0 \mathrm{mg} \mathrm{KOH} / \mathrm{g}$, which corresponds to a conversion close to $100 \%$. Results presented in Fig. 8 also revealed that for the shorter alkyl chain in the imidazolium cation of the IL, the catalytic effect is stronger. For the IL $\left[\mathrm{C}_{6} \mathrm{mim}\right] \mathrm{HSO}_{4}$ the epoxide value $L_{\mathrm{ep}}=0 \mathrm{mg}$ $\mathrm{KOH} / \mathrm{g}$ was obtained just after a reaction time $5 \mathrm{~h}$. Fig. 8 summarizes the results of syntheses, in which in the studied reaction different catalytic systems were used: $1 \mathrm{wt} \%$ aqueous solution of $\mathrm{H}_{2} \mathrm{SO}_{4}$ containing the $\mathrm{IL}$ and either a quaternary ammonium salt, and $\mathrm{H}_{2} \mathrm{SO}_{4}$ and the IL used separately.

Results of these studies clearly confirmed the dual functionality of the amphiphilic ILs. This is clearly seen when comparing the two catalytic systems $1 \% \mathrm{H}_{2} \mathrm{SO}_{4} / \mathrm{IL}$ and $1 \%$

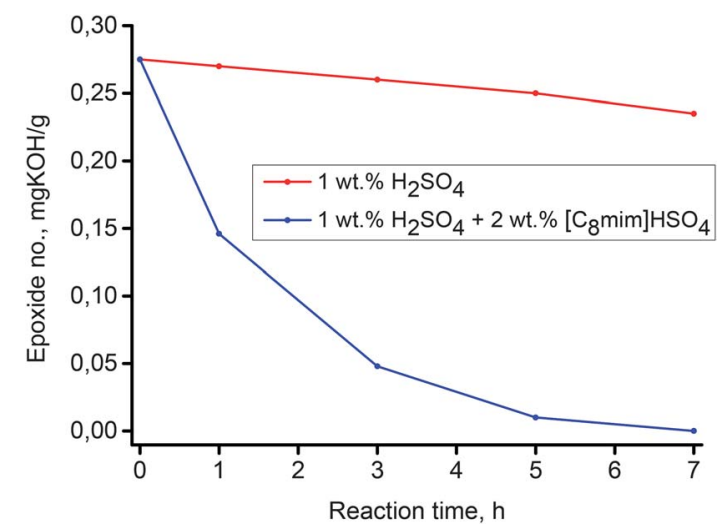

Fig. 7 Effect of ionic liquid addition on epoxide number changes (reaction condition: $T=80^{\circ} \mathrm{C}$ ).

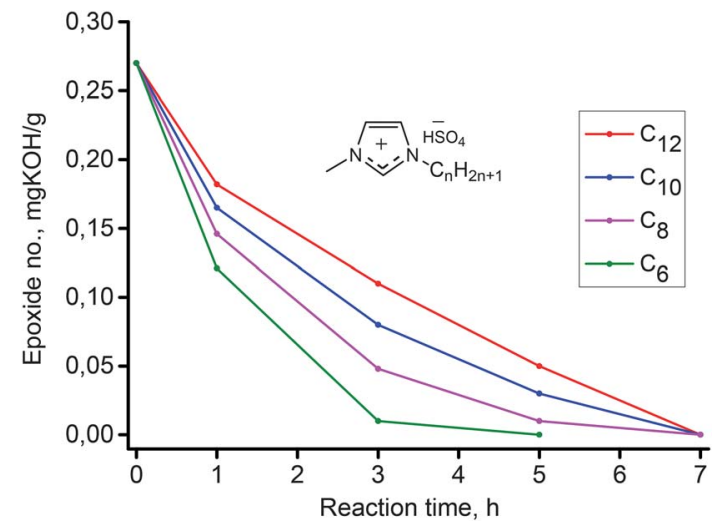

Fig. 8 Effect of alkyl chain length in 1-alkyl-3-methylidazolium hydrogen sulfate ionic liquids used as co-catalyst in reaction of hydrolysis of epoxidized methyl oleate.

$\mathrm{H}_{2} \mathrm{SO}_{4} /$ common quaternary ammonium salt, OTMAC. In comparison to the classical ammonium salt surfactant, the IL has a significantly stronger co-catalytic effect. For the $1 \%$ $\mathrm{H}_{2} \mathrm{SO}_{4} / \mathrm{IL}$ system a faster growth in the conversion of epoxide was observed. After a reaction time of $7 \mathrm{~h}$, the conversion of epoxide was almost $100 \%$, while for the $1 \% \mathrm{H}_{2} \mathrm{SO}_{4} / \mathrm{OTMAC}$ after the same time, it was only $80 \%$. For comparison, results obtained for $\mathrm{H}_{2} \mathrm{SO}_{4}$, and the $\mathrm{IL}\left[\mathrm{C}_{8} \mathrm{mim}\right] \mathrm{HSO}_{4}$ used independently as a main catalyst are shown in Fig. 8. The strong mineral acid showed much weaker catalytic ability than the $\mathrm{H}_{2} \mathrm{SO}_{4} / \mathrm{IL}$ mixture; however, the IL by itself was characterized by only a little higher activity compared to $\mathrm{H}_{2} \mathrm{SO}_{4}$.

Examining the reaction of water addition to the epoxide ring, its selectivity should also be taken into account. It is known that nucleophilic addition to the oxirane ring, using the $\mathrm{S}_{\mathrm{N}} 1$ mechanism, leads to the formation of two products. The main product of the addition corresponds to a 1,2-diol (Scheme 2). Under the reaction conditions (presence of aqueous solution of acid catalysts at elevated temperatures) may, however, take place the isomerization of the epoxide ring leading to the ketone (Scheme 3). ${ }^{51}$

The isomerization reaction of the oxirane ring is catalyzed by Lewis acids. The key step is the creation of a hydrogen bond with the oxirane oxygen atom. Imidazolium ILs are also known, often under the reaction conditions, to behave as typical Lewis catalysts. In particular, the imidazolium cation may act as a Lewis acid, which is reflected, among other things, by the formation of hydrogen bonds with a $\mathrm{C}_{2}-\mathrm{H}$ hydrogen atom. ${ }^{52-54}$ In the case of epoxy compounds in the presence of imidazolium ILs the following complexes may be formed ${ }^{55}$ (Scheme 4).

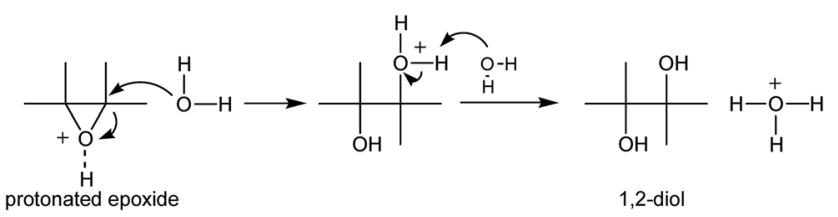

Scheme 2 Nucleophilic addition of water to epoxide, by the 1,2-diol route. 

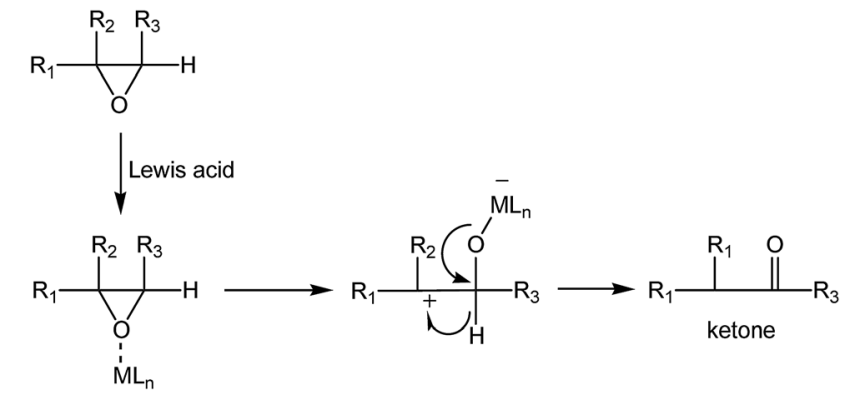

Scheme 3 A Lewis acid catalyzed isomerization of epoxide, by the ketone route.

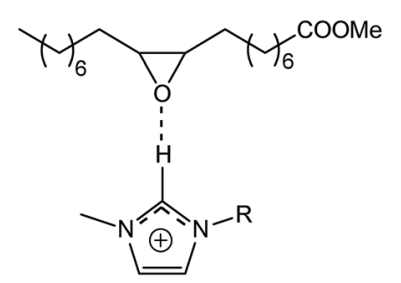

Scheme 4 Ionic liquid - epoxy FAME complex.

Accordingly, as a results of water addition to the epoxidized FAME, two types of products can be created (Scheme 5). An evaluation of the surface properties of the homologous series of the 1-alkyl-3-methyloimidazolium ILs was presented in a previous section. Based on those results, the effect of the ILs structure in the reaction of a nucleophilic addition of water to epoxidized FAME was investigated. The results obtained are shown graphically in Fig. 6-8. Considering the theoretical assumptions shown in Scheme 4, the assessment of the IL impact on the selectivity of the addition reaction was performed. The results are summarized in Table 3 .

Just as it did when assessing the effect of the alkyl chain length on the co-catalytic effect, the alkyl chain length also has a noticeable impact on the selectivity of the reaction studied. The highest concentration of $\left[\mathrm{C}_{6} \mathrm{mim}\right] \mathrm{HSO}_{4}$ IL causes the highest effect on the oxirane ring - imidazolium cation structure showed in Scheme 4. Formation of this structure favors the formation of the side product - ketone (Table 3, entry 5) compared to reaction conducted in absence of the IL (Table 3, entries 1, 2 and 3). In Fig. 9 a representative GC chromatogram of reaction product is presented.

The results presented in Table 3 clearly show that the type of catalytic system has a noticeable effect on reaction selectivity.
Table 3 Results of addition of water to epoxidized fatty acid methyl esters, effect of catalyst on selectivity of reaction (reaction time $-7 \mathrm{~h}$; temp. $\left.-80^{\circ} \mathrm{C}\right)$

\begin{tabular}{llllll}
\hline $\begin{array}{l}{\left[\mathrm{C}_{n} \mathrm{mim}\right] \mathrm{HSO}_{4}} \\
\text { Entry }(\mathrm{wt} \%)\end{array}$ & $\begin{array}{l}\mathrm{H}_{2} \mathrm{SO}_{4} \text { aq. } \\
(\mathrm{wt} \%)\end{array}$ & $\begin{array}{l}\text { Conversion } \\
(\%)\end{array}$ & $\begin{array}{l}\text { Selectivity } \\
\text { to diol (\%) }\end{array}$ & $\begin{array}{l}\text { Selectivity } \\
\text { to ketone (\%) }\end{array}$ \\
\hline 1 & - & 5 & 100 & 84.5 & 15.5 \\
2 & - & 2 & 100 & 83.9 & 16.1 \\
3 & & 1 & 16.4 & 83.3 & 16.7 \\
4 & $\mathrm{C}_{10}, 5 \mathrm{wt} \%$ & 1 & 100 & 79.2 & 20.8 \\
5 & $\mathrm{C}_{6}, 2 \mathrm{wt} \%$ & 1 & 100 & 66.6 & 33.4 \\
6 & $\mathrm{C}_{8}, 2 \mathrm{wt} \%$ & 1 & 99.1 & 74.5 & 25.5 \\
7 & $\mathrm{C}_{10}, 2 \mathrm{wt} \%$ & 1 & 99.3 & 76.7 & 23.3 \\
8 & $\mathrm{C}_{12}, 2 \mathrm{wt} \%$ & 1 & 99.3 & 78.9 & 22.1 \\
9 & $\mathrm{C}_{14}, 2 \mathrm{wt} \%$ & 1 & 99.2 & 79.4 & 21.8 \\
\hline
\end{tabular}

The reaction carried out in the presence of $\mathrm{H}_{2} \mathrm{SO}_{4}$ alone was strongly directed to 1,2-diol. The selectivity to diol was 83.3$84.5 \%$ and did not depend on the acid concentration. The selectivity to the ketone was $16.7-15.5 \%$. Application of the amphiphilic IL as a co-catalyst shifts the reaction a little more towards the ketone. For the catalytic system $1 \mathrm{wt} \% \mathrm{H}_{2} \mathrm{SO}_{4} / \mathrm{IL}$ selectivity to 1,2-diol was $66.6-79.2 \%$ and the selectivity to the ketone was $33.4-20.8 \%$. Furthermore, the results presented in Table 1 clearly show that the selectivity to 1,2-diol and ketone depends on the length of the alkyl chain in the IL. When the alkyl substituent is shorter, the content of the ketone in the post-reaction mixture is greater. These results are consistent with those described in the literature for the effects of the chain alkyl length of imidazolium ILs on their physicochemical properties.

\subsection{Discussion of the catalytic activity}

The systems that exhibit the highest efficiency of the catalytic opening of the epoxide ring is the epoxidized methyl oleate in the biphasic system containing $1 \mathrm{wt} \%$ of $\mathrm{H}_{2} \mathrm{SO}_{4}$ and $2 \mathrm{wt} \%$ of $\left[\mathrm{C}_{6} \mathrm{mim}\right] \mathrm{HSO}_{4}$ or $\left[\mathrm{C}_{8} \mathrm{mim}\right] \mathrm{HSO}_{4}$. For those ILs, the epoxide number equal to $0 \mathrm{mg} \mathrm{KOH} / \mathrm{g}$, reflecting epoxide conversion of almost $100 \%$, was obtained after just $5 \mathrm{~h}$ of the reaction time. In this respect, addition of the acidic 1-hexyl- or 1-octyl-3methylimidazolium IL revealed the highest synergistic effect providing a strong increase of the reaction rate in the comparison to the system without the IL. Furthermore, these systems also revealed a higher catalytic activity than the analogous catalytic system containing $1 \% \mathrm{H}_{2} \mathrm{SO}_{4} / \mathrm{OTMAC}$, and this was only an $80 \%$ conversion after $7 \mathrm{~h}$. The crucial difference

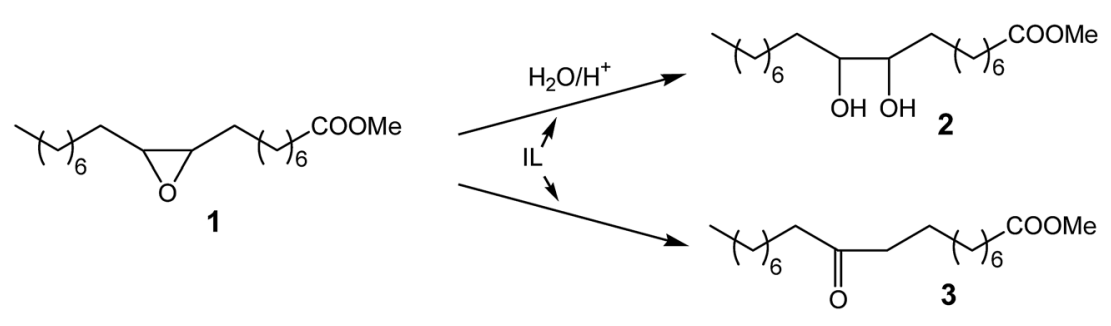

Scheme 5 Nucleophilic addition of water to epoxidized FAME, alternative route. 


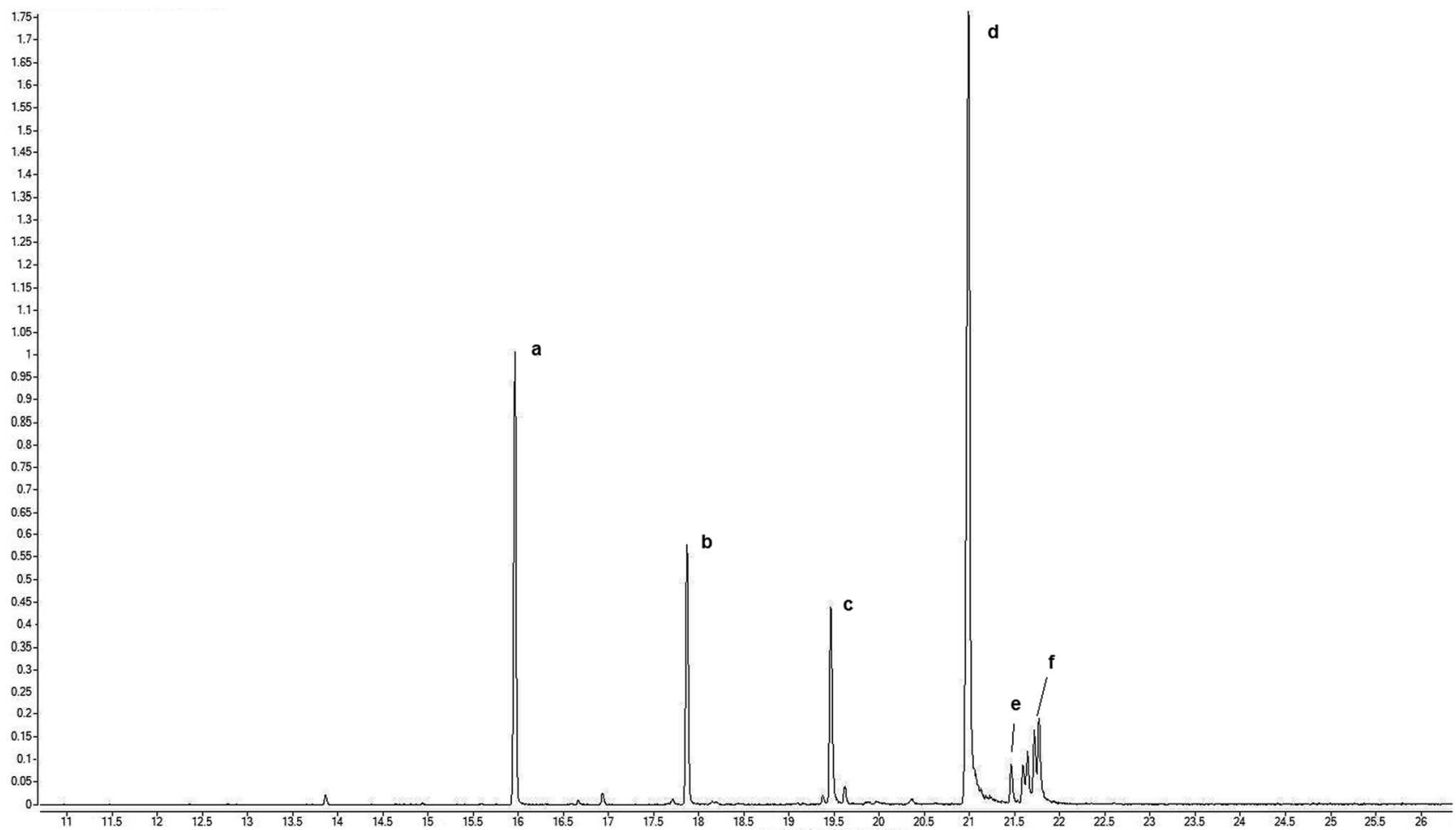

Fig. 9 Representative GC chromatogram of products of reaction; (a) - fatty acid $C_{16}$ methyl ester; (b) - fatty acid $C_{18}$ methyl ester; (c) - ketone 3; (d) - glycol 2, (e) - epoxy oleic acid methyl ester; (f) - diepoxides and diglycols.

between imidazolium and ammonium compounds is the presence of the acidic $\mathrm{C}_{2}-\mathrm{H}$ hydrogen atom in the imidazolium ring that may interact with the oxygen atom in the oxirane ring. Dong et al., studying the physicochemical properties of the alkylimidazolium ILs, have shown experimentally that the number of the carbon atoms in the alkyl chain have a noticeable effect on the $\mathrm{C}_{2}-\mathrm{H}$ bond length. ${ }^{55}$ For longer alkyl chains, the $\mathrm{C}_{2}-\mathrm{H}$ bond is shorter, thus affecting the acidity of this proton. Therefore, elongation of the alkyl substituent in the imidazolium ILs decreases the $\mathrm{pKa}$ of the imidazolium cation, which is characterized by lower acidity. This affects the low stability $\mathrm{C}_{2}-\mathrm{H}-\mathrm{O}$ (epoxy) hydrogen bonds and consequently the stability of the hydrogen complexes oxirane-IL. This observation was also confirmed by studies conducted for model systems using nuclear magnetic resonance spectroscopy ${ }^{56-59}$ The ILs containing long alkyl chains, for example $\mathrm{R}=\mathrm{C}_{10}$, shifts the reaction of the water addition to epoxidized FAME towards the more preferred dihydroxy compound (1,2-diol). In turn, in the presence of the ILs with shorter alkyl chains, for example $\mathrm{R}=\mathrm{C}_{6}$, a side reaction towards the ketone becomes a bit more important.

The higher catalytic activity of the system containing IL can be related to the surface properties of the ILs. Because of the amphiphilic structure, the IL reveals the ability to adsorb at the oil/water interface and form micellar aggregates in the aqueous phase. Therefore, epoxidized methyl oleate may diffuse to the aqueous-organic interface, where it interacts with IL ions, followed by the increase of the solubility in the aqueous phase via their incorporation into the micelles (solubilization). Analysis of the dependence of the alkyl chain length on the surface properties of 1-alkyl-3-methylimidazolium ILs, in particular on the CMC values, revealed that the shorter the alkyl chain length $\left(\mathrm{C}_{6}\right)$, the higher the critical concentration representing micelle formation. The effect of the alkyl chain length on the CMC values of the homologous series of alkylimidazolium hydrogen sulfate ILs is presented in Table 1 and Fig. 5 . It should be mentioned that $2 \mathrm{wt} \%$ concentration of the ILs added to the reaction system exceeds the CMC values only for the systems containing ILs with $\mathrm{C}_{10}-\mathrm{C}_{14}$ alkyl chain length. This means that for only these compounds can micelle formation be expected. For a $\mathrm{C}_{8} \mathrm{IL}$, the concentration applied in the experiment exceeded the concentration needed to decrease the surface tension by $20 \mathrm{mN} \mathrm{m}^{-1}$ which is the figure that has been identified to give complete (or close to complete) saturation of the interface. On the contrary, $\left[\mathrm{C}_{6} \mathrm{mim}\right] \mathrm{HSO}_{4}$ was used at a concentration that was lower not only than the CMC but also lower than the $\mathrm{C}_{20}$ concentration meaning that saturation of the interface was not attained. It should also be remembered that ILs reveal some affinity not only to water but also towards the organic fatty acid phase because of the presence of the hydrophobic part of the cation. Some partial solubility of the IL in the organic phase results in a decrease of the $\left[\mathrm{C}_{6} \mathrm{mim}\right] \mathrm{HSO}_{4}$ at the interface. In addition, ILs with a shorter alkyl chain length are also characterized by the higher specific surface area values per IL ion pair at the interface $\left(0.87 \mathrm{~nm}^{2}\right.$ for $\left[\mathrm{C}_{6} \mathrm{mim}\right] \mathrm{HSO}_{4}$ and $0.67 \mathrm{~nm}^{2}$ for $\left.\left[\mathrm{C}_{14} \mathrm{mim}\right] \mathrm{HSO}_{4}\right)$. That is, the cross-sectional area occupied by the amphiphilic compounds with shorter alkyl chain is higher. The short chained ILs are not in the closed- 
packed arrangement to the surface normally but are probably more tilted with respect to the interface than the long chained ones. As a consequence, the maximum surface excess concentration, that describes the effectiveness of the amphiphile adsorption, is lower for ILs with shorter alkyl chains. Based on these results, it can be assumed that adsorption of the ILs at the oil/water interface rather than micellization/solubilization processes plays a crucial role in the mechanism of the epoxide conversion. Adsorption of the ILs at the interface results in a lowering of the interfacial tension facilitating contact of the substrates in both phases. In addition, the length of the alkyl chain also influences the strength of the interaction between cations and anions of the IL. That is, the longer the hydrocarbon chain, the more delocalized is the charge, the more acidic the imidazolium $\mathrm{H}_{2}$ hydrogen atom is, and as a consequence the weaker is the interaction between ions. From this perspective, ILs with a higher catalytic activity $\left(\mathrm{C}_{6}-\mathrm{C}_{8}\right)$ are characterized by the strongest cation-anion interactions and a lower acidity of the $\mathrm{C}_{2}-\mathrm{H}$ hydrogen atom. On the other hand, elongation of the alkyl chain in the imidazolium cation may also result in stronger van der Waals interactions between hydrocarbons (shown as higher surface excess) and additional steric hindrance limiting ability of the imidazolium cation to interact with the organic substrate. A similar conclusion has been reported by $\mathrm{Xu}$ et $a l^{60}{ }^{60}$ in his study on dissolution of cellulose in 1-alkyl-3-methylimidazolium ILs. The increasing alkyl chain length leads to an increase in the acidity of the hydrogen atoms $\mathrm{H}_{2}$ and $\mathrm{H}_{4}$ in the imidazolium cation which contributes to the hydrogen bond formation between the acidic hydrogen and the hydroxyl oxygen of cellulose, and thus, cellulose dissolution. However, as the alkyl chain length increases further, the steric hindrance of the hydrogen bond formation between the acidic hydrogen and the hydroxyl oxygen increases, and the hydrophilicity of the imidazolium cation decreases, which is not conducive to cellulose dissolution.

\section{Conclusions}

In summary, a series of amphiphilic 1-alkyl-3methylimidazolium hydrogen sulfate ILs were synthesized and analyzed to determine their surface and co-catalytic properties. Surface properties (surface tension, micellization, degree of ionization of micelles and Krafft temperatures) were determined. The length of the alkyl chain substituents was found to have a vital effect on the adsorption and micellization behavior. All the acidic ILs were tested as co-catalysts in an oxirane ring opening reaction in epoxidized FAME. Their co-catalytic activities were studied as a function of surface and physicochemical properties. It was found that the co-catalytic properties, both conversion and selectivity, of the alkylimidazolium hydrogen sulfate ILs depend noticeably on the alkyl chain lengths attached to imidazolium nitrogen atom, the acidity of the $\mathrm{C}_{2}-\mathrm{H}$ imidazolium hydrogen atom and the micellization properties. The surface properties of 1-alkyl-3-methylimidazolium hydrogen sulfate ILs were found to have a noticeable impact on the co-catalytic effect, whereas the acidity of the $\mathrm{C}_{2}-\mathrm{H}$ hydrogen atom influences the selectivity of this reaction. The results obtained confirm the specific dual functionality of the amphiphilic Brønsted acidic ILs.

\section{Acknowledgements}

The authors acknowledge funding from the National Science Center (contract no. 2012/05/B/ST4/02023) and from the Polish Ministry of Science and Higher Education for Statutory Research. This work has been done within the frameworks of COST Actions MP1106 "Smart and green interfaces - from single bubbles and drops to industrial, environmental and biomedical applications (SGI) and CM1206 "EXIL - Exchange on Ionic Liquids".

\section{References}

1 F. Maier, T. Cremer, C. Kolbeck, K. R. J. Lovelock, N. Paape, P. S. Schulz, P. Wasserscheid and H. P. Steinruck, Phys. Chem. Chem. Phys., 2010, 12, 1905-1915.

2 U. P. Preiss, P. Eiden, J. Łuczak and C. Jungnickel, J. Colloid Interface Sci., 2013, 412, 13-16.

3 J. Łuczak, C. Jungnickel, M. Markiewicz and J. Hupka, J. Phys. Chem. B, 2013, 117, 5653-5658.

4 T. Inoue, H. Ebina, B. Dong and L. Zheng, J. Colloid Interface Sci., 2007, 314, 236-241.

5 M. Poleski, M. Łuczak, R. Aranowski and C. Jungnickel, Physicochem. Probl. Miner. Process., 2013, 49, 277-286.

6 J. Łuczak, C. Jungnickel, I. Lacka, S. Stolte and J. Hupka, Green Chem., 2010, 12, 593-601.

7 M. G. Freire, P. J. Carvalho, A. M. Fernandes, I. M. Marrucho, A. J. Queimada and J. A. P. Coutinho, J. Colloid Interface Sci., 2007, 314, 621-630.

8 P. Brown, C. P. Butts, J. Eastoe, D. Fermin, I. Grillo, H.-C. Lee, D. Parker, D. Plana and R. M. Richardson, Langmuir, 2012, 28, 2502-2509.

9 C. S. Santos and S. Baldelli, J. Phys. Chem. B, 2009, 113, 923933.

10 J. Łuczak, J. Hupka, J. Thöming and C. Jungnickel, Colloids Surf., A, 2008, 329, 125-133.

11 N. A. Smirnova and E. A. Safonova, Russ. J. Phys. Chem. A, 2010, 84, 1695-1704.

12 P. Brown, C. Butts, R. Dyer, J. Eastoe, I. Grillo, F. Guittard, S. Rogers and R. Heenan, Langmuir, 2011, 27, 4563-4571.

13 M. Tariq, M. G. Freire, B. Saramago, J. A. P. Coutinho, J. N. C. Lopes and L. P. N. Rebelo, Chem. Soc. Rev., 2012, 41, 829-868.

14 T. L. Greaves and C. J. Drummond, Chem. Soc. Rev., 2008, 37, 1709-1726.

15 Z. Miskolczy, K. Sebők-Nagy, L. Biczók and S. Göktürk, Chem. Phys. Lett., 2004, 400, 296-300.

16 R. Vanyúr, L. Biczók and Z. Miskolczy, Colloids Surf., A, 2007, 299, 256-261.

17 C. Jungnickel, J. Łuczak, J. Ranke, J. F. Fernández, A. Müller and J. Thöming, Colloids Surf., A, 2008, 316, 278-284.

18 J. Łuczak, M. Markiewicz, J. Thöming, J. Hupka and C. Jungnickel, J. Colloid Interface Sci., 2011, 362, 415-422. 
19 P. D. Galgano and O. A. El Seoud, J. Colloid Interface Sci., 2011, 361, 186-194.

20 X. Fan and K. Zhao, J. Phys. Chem. B, 2014, 118, 13729-13736.

21 B. L. Bhargava and M. L. Klein, Mol. Phys., 2009, 107, 393401.

22 J. Li, J. Liang, W. Wu, S. Zhang, K. Zhang and H. Zhou, New J. Chem., 2014, 38, 2508-2513.

23 R. Jusoh, A. A. Jalil, S. Triwahyono, A. Idris, S. Haron, N. Sapawe, N. F. Jaafar and N. W. C. Jusoh, Appl. Catal., A, 2014, 469, 33-44.

24 G. Lv, Z. Li, W.-T. Jiang, S. Xu and T. E. Larson, Green Chem. Lett. Rev., 2014, 7, 191-198.

25 V. Pino, J. L. Anderson, J. H. Ayala, V. González and A. M. Afonso, J. Chromatogr. A, 2008, 1182, 145-152.

26 J. Bender, D. Jepkens and H. Hüsken, Org. Process Res. Dev., 2010, 14, 716-721.

27 N. M. T. Lourenço and C. A. M. Afonso, Tetrahedron, 2003, 59, 789-794.

28 S. S. Shinde, H. M. Chi, B. S. Lee and D. Y. Chi, Tetrahedron Lett., 2009, 50, 6654-6657.

29 A. Perosa, P. Tundo, M. Selva, S. Zinovyev and A. Testa, Org. Biomol. Chem., 2004, 2, 2249-2252.

30 L.-W. Xu, Y. Gao, J.-J. Yin, L. Li and C.-G. Xia, Tetrahedron Lett., 2005, 46, 5317-5320.

31 D. W. Kim, C. E. Song and D. Y. Chi, J. Am. Chem. Soc., 2002, 124, 10278-10279.

32 S. V. Bhilare, N. B. Darvatkar, A. R. Deorukhkar, M. S. Rasalkar and M. M. Salunkhe, Synth. Commun., 2007, 37, 3111-3117.

33 J. S. Yadav, B. V. S. Reddy, M. S. Reddy, N. Niranjan and A. R. Prasad, Eur. J. Org. Chem., 2003, 9, 1779-1783.

34 J. Fraga-Dubreuil, K. Bourahla, M. Rahmouni, J. P. Bazureau and J. Hamelin, Catal. Commun., 2002, 3, 185-190.

35 V. Kumar, I. Jamie Talisman, O. Bukhari, J. Razzaghy and S. V. Malhotra, RSC Adv., 2011, 1, 1721-1727.

36 B. Gilbert, H. Olivier-Bourbigou and F. Favre, Oil Gas Sci. Technol., 2007, 62, 745-759.

37 F. Shi, H. Xiong, Y. Gu, S. Guo and Y. Deng, Chem. Commun., 2003, 1054-1055.

38 A. Alizadeh, M. M. Khodaei and A. Eshghi, J. Org. Chem., 2010, 75, 8295-8298.

39 B. Moser, B. Sharma, K. Doll and S. Erhan, J. Am. Oil Chem. Soc., 2007, 84, 675-680.
40 J. Gao, J. Liu, B. Li, W. Liu, Y. Xie, Y. Xin, Y. Yin, X. Jie, J. Gu and Z. Zou, New J. Chem., 2011, 35, 1661-1666.

41 R. Zana, Langmuir, 1996, 12, 1208-1211.

42 N. Jiang, P. Li, Y. Wang, J. Wang, H. Yan and R. K. Thomas, J. Colloid Interface Sci., 2005, 286, 755-760.

43 J. Łuczak, C. Jungnickel, M. Joskowska, J. Thöming and J. Hupka, J. Colloid Interface Sci., 2009, 336, 111-116.

44 T. E. Cosgrove, Colloid Science: Principles, Methods and Applications, John Wiley \& Sons, Ltd, Publication, 2010.

45 K. Bouchemal, F. Agnely, A. Koffi, M. Djabourov and G. Ponchel, J. Mol. Recognit., 2010, 23, 335-342.

46 K. Beyer, D. Leine and A. Blume, Colloids Surf., B, 2006, 49, 31-39.

47 F. Geng, J. Liu, L. Zheng, L. Yu, Z. Li, G. Li and C. Tung, J. Chem. Eng. Data, 2010, 55, 147-151.

48 Y. Wei, F. Wang, Z. Zhang, C. Ren and Y. Lin, J. Chem. Eng. Data, 2014, 59, 1120-1129.

49 L. Shi, N. Li, H. Yan, Y. A. Gao and L. Zheng, Langmuir, 2011, 27, 1618-1625.

50 M. J. Rosen, Surfactants and Interfacial Phenomena, John Wiley \& Sons, Inc., New Jersey, 3rd edn, 2004.

51 R. J. Hunter, Foundations of Colloid Science, Oxford University Press Inc., New York, 2002.

52 A. Aggarwal, N. L. Lancaster, A. R. Sethi and T. Welton, Green Chem., 2002, 4, 517-520.

53 A. R. Gholap, K. Venkatesan, T. Daniel, R. J. Lahoti and K. V. Srinivasan, Green Chem., 2003, 5, 693-696.

54 S. A. Forsyth, D. R. MacFarlane, R. J. Thomson and M. von Itzstein, Chem. Commun., 2002, 714-715.

55 K. Dong, S. Zhang, D. Wang and X. Yao, J. Phys. Chem. A, 2006, 110, 9775-9782.

56 T. L. Amyes, S. T. Diver, J. P. Richard, F. M. Rivas and K. Toth, J. Am. Chem. Soc., 2004, 126, 4366-4374.

57 J. Zhang, H. Zhang, J. Wu, J. Zhang, J. He and J. Xiang, Phys. Chem. Chem. Phys., 2010, 12, 1941-1947.

58 K. Zhuo, Y. Chen, J. Chen, G. Bai and J. Wang, Phys. Chem. Chem. Phys., 2011, 13, 14542-14549.

59 J. M. M. Araújo, A. B. Pereiro, J. N. Canongia Lopes, L. P. N. Rebelo and I. M. Marrucho, J. Phys. Chem., 2013, 117, 4109-4120.

60 A. Xu, L. Cao, B. Wang and J. Ma, Adv. Mater. Sci. Eng., 2015, 4, 406470 . 